\title{
Educação, militantismo católico e Filosofia no Brasil
}

Resumo: Esteartigo propõe uma reflexão sobrea relação entreeducação, militância política católicae Filosofia no Brasil. Trata-se depensar como a passagem pelo militantismo político em movimentos dejuventude católica (J uventude U niversitária C atólica eJ uventudeEstudantil Católica) seconstituiu em um lócus de socialização importantepara osmentores dos primeiros dispositivosquecontribuíram paraainstitucionalização da produção filosófica universitáriano Brasil. 0 material empírico coletado para análisefoi composto deentrevistas semi-estruturadas com 17 filósofos, observações etnográficas, depoimentos publicados, além de informações coletadasna base dedadosinstitucionais (Plataforma Lattes, CN Pq).

Palavras-chave: Filosofia no Brasil; militância política católica; filósofos brasileiros; institucionalização daFilosofia no Brasil; militância política eFilosofiano Brasil.

Education, catholic militancy and philosophy in Brazil

Abstract: This articleproposes a reflection on therelations between education, catholic political militancy and philosophy in Brazil. It examines how the experience of political militancy in youngsters' catholic movements (J uventudeU niversitária Católica and JuventudeE studantil Católica) was constituted as an important socialization locus to the mentors of thefor thefirst actions of theinstitutionalization of the university philosophical production in Brazil. The empiric material collected for analysis consisted of semi-structured interviews with 17 philosophers, ethnographic notes, and published testimonies, besidestheinformation collected from the institutional data basis (Plataforma Lattes, CN Pq).

Key words: philosophy in Brazil; catholic political militancy; Brazilian philosophers; the institutionalization of philosophy in Brazil; political militancy.

\section{Introdução}

Ao contrário da França e da Alemanha, no Brasil, a Filosofia enquanto disciplina autônoma, isto é, com espaços específicos de difusão e produção e composta por um conjunto de regras, de métodos e por um corpo de professores especializados na transmissão dos conteúdos, só se firmou no país nos últimos

\footnotetext{
* Professora do Departamento de Psicologia e Orientação Educacional (DPOE) da Universidade Federal de Pernambuco (UFPE), Recife, Pernambuco, Brasil.dmffr@yahoo.fr
} 
30 anos, em particular, no final da década de 1970 (N obre; Rego, 1999; Ferreira, 2001).

Até então, a Filosofia praticada e lecionada no Brasil, embora presente na grade curricular nos cursos universitários espalhados pelo país, objetivava uma formação profissionalizante, ou seja, formar professores para o ensino secundário, e não uma formação filosófica baseada na pesquisa (Paim, 1984). Isso possibilitou o surgimento de uma reflexão filosófica mais autônoma em relação às demais disciplinas universitárias (Ferreira, 2001).

Foi somente a partir da década de 1970 e durante toda a década de 1980, com o investimento do Estado na formação de recursos humanos, na implantação da Pós-G raduação e na ordenação do sistema de financiamento à pesquisa, que a produção filosófica universitária se firmou no país; foi a partir daí que surgiram as primeiras publicações de revistas especializadas, as associações e os grupos de estudos controlados pelos próprios professores de Filosofia (Ferreira, 2007).

Por outro lado, se as políticas de Ciência e Tecnologia implementadas pelo Estado conferiram importância decisiva para a consolidação de espaços de discussões autônomos para produção filosófica no país, bem como a sua profissionalização, é importante lembrar que a constituição desses dispositivos dependeu, em grande parte, dos recursos sociais mobilizados pelos filósofos mentores desse processo. N essa perspectiva, a formação de um lugar de difusão e de consagração do conhecimento filosófico universitário brasileiro pode ser visto como resultado de um encontro entre a conjuntura política das décadas de 1970 e 1980, período marcado pela reorganização do sistema de ensino superior e pelo processo de redemocratização do país, e as propriedades sociais utilizadas por um conjunto de filósofos. Chama atenção, em especial, e esse é o objeto central deste artigo, a incorporação de determinados recursos sociais durante a passagem pelo militantismo político de esquerda católica dos filósofos: seja nos movimentos de juventude católica, como a Juventude U niversitária C atólica (JUC) e a Juventude Estudantil Católica (JEC), seja em partidos políticos de origem católica, como a Ação Popular (AP). Assim, este artigo está pautado numa reflexão acerca das especificidades da socialização e da formação dos filósofos durante suas atuações políticas, levando em consideração tanto as condições objetivas dessa militância quanto as disposições subjetivas e sua relação com a produção filosófica universitária no Brasil.

0 material utilizado para pensar essa socialização e sua relação com a criação, por exemplo, da Sociedade de Estudos e Atividades Filosóficas (SEAF), criada em 1975, e a Associação N acional de Pós-Graduação em Filosofia (AN PO F), fundada em 1983, bem como os programas de pós-graduação em Filosofia e as revistas especializadas na área, foi composto por: (1) informações 
extraídas da literatura sobre a Filosofia no Brasil, (2) entrevistas semi-estruturadas com um total de 25 professores de Filosofia, (3) observações de colóquios, (4) depoimentos sobre a formação social e intelectual dos filósofos, publicados em revistas e em memoriais acadêmicos e (5) banco de dados de instituições especializadas (Plataforma Lattes do CN Pq e páginas de universidades).

\section{Recursos familiares e militância política católica}

Para compreender de que modo se deu o processo de socialização dos filósofos nos movimentos de juventude católica é preciso explicitar as características sociais dos agentes recrutados pelos principais assistentes intelectuais, os religiosos da O rdem de São D omingos e da Companhia de J esus, para a formação do seu laicato.

Sendo assim, chama atenção o elevado volume de capital cultural e financeiro familiar dos filósofos cooptados pelos religiosos. A gestão desses dois capitais permite esclarecer não apenas o tipo de vínculo dos filósofos com a I greja Católica, mas, sobretudo, os diferentes graus de envolvimento que eles mantiveram com os movimentos políticos em que atuaram (JEC, JUC e AP): da organização de manifestações, passando pela formação política e intelectual de militantes, até a redação de manifestos. Assim, com exceção de dois filósofos (dos 17 entrevistados) que estabeleceram contato com a militância política por meio de seminário religioso, praticamente toda a população estudada que passou pelos movimentos de esquerda católica foi recrutada nas escolas públicas e privadas de elite onde estudavam. O riundos de famílias extremamente católicas, esses filósofos - filhos e sobrinhos de juristas, profissionais liberais, religiosos e, portanto, detentores de diplomas secundários ou universitários - contaram com o conhecimento e com a situação econômica de seus provedores para ingressar nessas escolas, locais privilegiados de atuação dos movimentos especializados da Ação Católica Brasileira (JEC e JUC). Além dos grandes colégios públicos, como o antigo Ginásio Estadual de Belo Horizonte ${ }^{2}$ onde estudou grande parte dos entrevistados, entre eles um dos grandes líderes da JU C, H erbert José de Souza, o Betinho (Ridenti, 2002, p.213-282) - , os movimentos especializados da Ação C atólica estendiam-se também a colégios privados de classe média, como o Colégio $M$ arconi, onde estudou o irmão de Betinho, H enfil, colega de classe de H ugo César Tavares e Walter Evangelista,

\footnotetext{
I. AAção Católica Brasileira foi um movimento criado em 1916, mas somente institucionalizado em 1934, por Dom Leme. Este tinha por objetivo fundamental uma espécie de "recristianização" da sociedade. Entre seus movimentos especializados destacam-se: a JEC, a JUC e a JOC.

2. Colégio conhecido pela formação de intelectuais e políticos nacionais importantes, como o Ministro da Educação Gustavo Capanema e o poeta Carlos Drummond de Andrade.
} 
ambos professores da UFM G, membros fundadores da SEAF e, posteriormente, da AN POF.

Esse mesmo fato foi observado por $M$ arcelo Ridenti, em sua pesquisa sobre a base social dos partidos políticos de esquerda das décadas de 1950 e 1960. Ao estabelecer uma morfologia social dos membros dos partidos de esquerda, partidos que fincavam suas bases no movimento de juventude católica, Ridenti afirma que apenas 4,2\% eram filhos de lavradores e 13,7\% de trabalhadores manuais urbanos. Esses números reiteram as evidências de que os espaços nos quais os religiosos à frente da Ação C atólica atuavam eram predominantemente oriundos de uma classe média escolarizada, destinada aos estudos universitários, conforme se pode observar com a população estudada (Ridenti, 1993).

O relato de Hugo César da Silva Tavares, ex-militante católico, professor de Filosofia aposentado da UFM G e membro fundador da SEAF, ajuda a compreender exatamente quais as estratégias arquitetadas e o público visado pelos religiosos no momento do recrutamento de seus militantes. Considerados os mais "espertos", esses estudantes de colégios públicos de elite de Belo H orizonte eram freqüentemente confrontados com a situação social em que viviam, 0 que era considerado pela I greja Católica algo passível de promover a interação e trazer esses jovens para o movimento.

\section{[...] eram pequenosnúdeos[...] pegavam osqueeram maisespertos efaziam assédio, atéfisgar. Eles(osreligiososdominicanos) eram mais fortesnasescol asle gasemunicipaiseetaduais. Era aí quedesti- nham osgruposmaisfervorosos[...] Elesdiziam, "o pessoal etá pas sando fome, vocêsetão fazendo o quepara mudar isso?" chegavam assim ea gentequeria interagi r. Vocêsabequeo jovem émuito al- truísa [...] N óséramosmuitojovens[...] era uma manera decana- lizar [...] etinha a distribuição deriquezas". (Entrevistacom H ugo César Tavares, realizada em 2004, cf. Ferreira, 2007, p. 77).}

Além de H ugo César da Silva Tavares, também cursaram os Colégios Estadual e M arconi, em Belo H orizonte, e militaram juntos na JEC, os filósofos José Walter Evangelista, Guido Antônio de Almeida e José de Anchieta Corrêa, todos envolvidos, posteriormente, na fundação da SEAF e da AN POF e nas discussões sobre os métodos e as regras de transmissão do conhecimento filosófico nos programas de pós-graduação no Brasil. Q uando realizaram estudos de Filosofia na Universidade Federal de M inas Gerais, todos os quatro participaram também da JUC.

A entrada nesses colégios de elite revela o peso dos indicadores sociais e culturais dos familiares desses filósofos. Como se pode observar em entrevistas, Raul Landim Filho, filho de advogado e de mãe professora de francês, e G uido de Almeida, neto de grande proprietário de fazendas e filho de funcionário do 
Estado, revelaram que seus familiares não pouparam esforços para garantir-Ihes uma educação escolar em espaços prestigiosos, como o semi-internato dos jesuítas no Rio de Janeiro e as escolas privadas de línguas estrangeiras.

Q uestionado sobre seu envolvimento com os movimentos de esquerda católica na década de 1950, Raul Landim Filho - membro fundador da AN PO F - referiu-se imediatamente ao colégio em que estudava, o semi-internato dos jesuítas, Colégio Anchieta, destinado à formação intelectual da elite católica do Rio de Janeiro, e à influência dos religiosos jesuítas, em particular do Padre Vaz, na difusão do movimento da JEC no colégio.

Eu sou deuma família católica [... ] extremamentecatólica. Quando eu vim para o Rio, eu fui estudar no colégio Anchieta, o colégio dos jesuítas[...] era um bom colégio católico tradicional [...] lá conhedi PadreVaz [...] atravésdeseusescritos(artigos) publicadosna revista Síntese, publicação dosjesuítasequeli por volta dosmeus 16, 17 anos [...]. (Entrevista com Raul Landim Filho, realizada em 2002, cf. Ferreira, 2007, p. 87).

A entrevista concedida por Antônio Muniz de Rezende, ex-diretor dos dominicanos, assistente geral da JEC e da JUC em M inas Gerais e professor de Filosofia da Educação na Unicamp, confirma o despertar (pós-1958) do interesse da I greja Católica pela América Latina, em razão da Revolução Cubana. Para esse dominicano que, ao lado do jesuíta Padre Vaz, era responsável pelo recrutamento de jovens nas escolas de Belo Horizonte e do Rio de Janeiro, 0 interesse na formação de um laicato cultural e intelectualmente instruído estava atrelado à necessidade e, portanto, ao interesse da I greja Católica em preparar um corpo pensante capaz de fazer frente aos líderes políticos e intelectuais militantes dos partidos comunista e socialista, que ganhará espaço, sobretudo, no final da década de 1950.

Assim, pode-se dizer que, tanto a seleção quanto a forma de recrutamento e a formação dos militantes nos movimentos católicos visavam a constituição de uma elite católica. Referindo-se à intenção da I greja no recrutamento de seus militantes, José de Anchieta Corrêa, membro fundador da Ação Popular e, na década de 1970, da Sociedade de Estudos e Atividades Filosóficas (SEAF/1975), afirma:

[...] $\mathrm{N}$ a verdade, éum nomeruim, masera uma elitequea I greja estava formando. Sem dúvida. Tanto que, poucos dias depois do golpe, osjornaispublicaram em primeira página: "O smeninosdo poder". Eram eu, o Beinho, Raul, H ugo [...] nóstodos. (Entrevista com J osédeAnchietadeC orrêa, realizada em 2004, cf. Ferreira, 2007, pp. 80-81). 
Como se observa, o depoimento acima deixa entender que a base social dos militantes que a I greja C atólica formaria, pelo menos daqueles que se dedicariam posteriormente à Filosofia, apoiava-se em uma classe social escolarizada e detentora de um poder aquisitivo bastante elevado.

Filosofia, recrutamento e formação militante

Ao tratar de suas atuações políticas, os filósofos entrevistados referem-se ao militantismo como a incorporação de uma série de saberes em termos práticos e teóricos. Por termos práticos, compreende-se 0 aprendizado adquirido durante a organização de reuniões, congressos e encontros estudantis regionais e nacionais: da simples divulgação e propaganda dos encontros, passando pela escolha dos locais e pelas inscrições dos participantes até a elaboração da pauta, temas a serem discutidos. Além disso, vale salientar que a grande maioria dos encontros estudantis realizados depois de 1964 foram articulados clandestinamente, visto que eram considerados espaços de subversão ao regime da época.

O uso desse aprendizado prático na constituição de espaços de discussão filosófica no Brasil pode ser evidenciado tanto nos depoimentos coletados por N obre e Rego, no livro Conversas com filósofos brasileiros (2000), quanto na pesquisa empírica na qual se baseia este artigo. É assim que, respondendo a pergunta sobre a formação da Sociedade de Estudos e Atividades Filosóficas (SEAF) na década de 1970, em plena clandestinidade, no Colégio Santa M arcelina, H ugo César da Silva Tavares, membro fundador dessa Sociedade, não hesitou em dizer que a organização das pessoas para o encontro de fundação da Associação foi quase inconsciente [...] nós já tínhamos a experiência dos movimentos (JEC e JUC), então foi inconsciente [...] foi o Olinto (O linto Pegoraro) que telefonou e nós falamos um com o outro, sem muito alarme. (Entrevista com H ugo César da Silva Tavares, realizada em 2004, cf. Ferreira, 2007, p. 79).

Por outro lado, se esse savoir-faire de caráter mais prático aparece como essencial na criação de dispositivos institucionais que firmaram um espaço mais autônomo para a produção da Filosofia no Brasil, foram os saberes de cunho mais teórico transmitidos e socializados entre os militantes e religiosos que se constituíram como determinantes para despertar 0 interesse de boa parte dos filósofos entrevistados pela Filosofia. E, neste ponto, foi de extrema importância o conhecimento filosófico e cultural mobilizado por dois religiosos em particular: 0 jesuíta Padre $\mathrm{H}$ enrique de Lima Vaz e o dominicano Frei M atheus Rocha. $O$ depoimento do líder da JU C, H erbert Souza, é claro nesse sentido, quando diz: "O padre Vaz foi nosso ideólogo, porque frei $M$ atheus foi 0 inspirador [...] Frei $M$ atheus Rocha foi fundador da JEC; enquanto o padre H enrique Vaz - leitor de M arx, Engels, H egel, H eidegger e outros pensadores 
- seria o redator da parte ideológica, teórica, filosófica, do documento fundador da AP" (Souza, 1982).

O uso da bagagem teórica utilizada por Padre Vaz e Frei M atheus, como assim eram chamados pelos militantes, funcionava como espécie de retórica de recrutamento aos movimentos católicos e como base indispensável na formação intelectual dos militantes. A declaração de José de Anchieta Corrêa, expresidente da SEAF, ilustra bem de que maneira os autores filosóficos eram mobilizados e transmitidos pelos assistentes da JEC e JUC.

Eu sou del tapecerica, uma cidademuito católica. Cidadequetem trêsbisposevim deuma família ultracatólica [...] vim para M inas estudar econheci osdominicanos. Eu meencante por aquela grandevirada: saí de uma catolicidade, entreo sexto mandamento eo sétimo, a respeito da propriedade e do sexo, e de repente, caí no mundo ecaí nosdominicanos, para quem crisão ésal da terra eluz do mundo. Éramoschamadospara essa participação na hi sória e política do seu tempo. Em M inas, havia um movimento sobre economia ehumanismo, havia grupos de leitura sobreEmanuel M ounier, Teilhard deChardin, etc. N ósfreqüentamostoda a literatura francesa de Claudel, Sartre e outros. No último ano do ginasial, da escola pública, nósconhecemosum dominicano chamado $F$ ré $M$ atheusRocha quefazia um movimento extremamente renovador de presença no mundo. Essesmovimentossedavam, sobretudo, nasescolaspúblicas, pelaschamadasequipesdeinfluência. E cada um de nós tinha uma equipe de influência. Então, fui cursar a universidadeeescolhi estudar Filosofia porqueeram daramenteaquelasidêasqueesávamosdiscutindo sobrevisão do mundo, valores 0 Frè M atheussemprecomeçava, perguntando quemé o homem? Elelia trechos das obras deSartre, também D ostoievski, vinha tudo. Somentedepoiselefalava em J esusC risto. (Entrevista com J osédeAnchietadeC orrêa, realizada em 2004, cf. Ferreira, 2007, pp. 80-81).

Assim, além da leitura das obras dos intelectuais do renouveau católico, como Emmanuel Mounier e Teilhard de Chardin, bem como a participação nos grupos de estudos de economia e de humanismo do dominicano LouisJoseph Lebret, os militantes freqüentavam e discutiam periodicamente, seja com Padre Vaz, seja com Frei M atheus, os autores da tradição filosófica clássica, como, por exemplo, os textos de Platão, D escartes, Kant e H egel.

Em recente entrevista, Paulo Arantes, filósofo aposentado da U SP, comenta que a grande novidade do Pe. Vaz era sua Filosofia da história, pois "[...] à Filosofia da imanência de $M$ arx era atribuída a noção de transcendência com as suas implicações [...] como era o caso da introdução da noção de pessoa do 
intelectual católico Emmanuel M ounier" (Arantes, 2005, p. 10). A discussão dessa "Filosofia da história", no dizer do filósofo uspiano, era regada de outras leituras filosóficas, que se tornaram decisivas para seu abandono do curso de física na USP e para a consolidação do seu interesse pela Filosofia na mesma universidade. Entre os livros que Ihe foram emprestados estavam os manuscritos econômicos de $M$ arx na edição francesa, além de livros de lógica matemática, fato que causou espanto a Arantes ao perceber "a vastidão do campo de interesse do Pe. Vaz".

Eu fui para a direção nacional da JU C em 1963 efoi nesse
momento que conheci pessoalmenteo Pe. Vaz, quejá erauma
espéciedelenda nessemeio em queeu passei aviver. N aépoca,
eu fazia física porque queria fazer Filosofia da Ciência,
Epistemologia, na U SP mesmo. Eu resolvi, portanto, meacon-
selhar com o Vaz, efiz várias vezes a viagem a N ova Friburgo,
ondeeledava aula, enquanto queeu morava no Rio de Janeiro
(capital), queeraa sede da Ação Católica. Elemetratava como
um aluno [...] D epois que lhe disse que tinha interesse pela
Filosofia, ele tirou de sua biblioteca pessoal três livros [...] As
Idéasl, do H usserl; osM anuscritosEconômico-Filosóficosdo jo-
vem M arx, de1944, erauma edição francesa, aEdition Sociale
[...] elemedisse: Leia isso; émuito importante[...] epor fim,
um livro delógicamatemática; o queeu não imaginava eraque
eletambém acompanhasseisso, maso homem acompanhava!
(Arantes, 2005, p.10)

M as não foi apenas em decorrência da leitura de autores de Filosofia, minuciosamente acompanhada pelos religiosos nos encontros semanais e quinzenais do M ovimento de Juventude Católica, que boa parte dos filósofos entrevistados acabou por investir no campo filosófico. Foi graças também à relação extramovimento que mantiveram com os religiosos que a Filosofia se tornou, para muitos desses ex-militantes, uma espécie de prolongamento da militância.

H ugo César da Silva Tavares, membro fundador da SEAF, falando do seu interesse pela Filosofia, aponta, sobretudo, a oportunidade que teve de atualizar a lista bibliográfica indicada por Padre Vaz, através de inúmeras discussões com o próprio religioso durante as reuniões do movimento e das visitas freqüentes à casa provincial dos jesuítas, em Belo H orizonte. Seu interesse pela Filosofia nasceu no secundário, durante o curso Científico seguido no Colégio $M$ arconi, onde conheceu Frei $M$ atheus e Pe. Vaz. Este último, contudo, foi essencial para a sua leitura de autores de textos filosóficos e para a escolha do curso de Filosofia. 
[...] uma pessoa queinfluenciou muita gentefoi o famoso Pe. Vaz, fundamental para minha escolha (dos estudosfilosóficos) ea do Walter (JoséWalter Evangelista, professor deFilosofia da U FM G). Foi dentro da militância dosmovimentos católicos. Elefoi fundamental. E como ele era mineiro, tínhamos muito contato aqui, embora elemorasseem $\mathrm{N}$ ova Friburgo. $\mathrm{Na}$ época, eu eWalter que ríamosfazer Engenharia eeu D ireito. Fomosconversar com ele(Pe Vaz), eelenosdeu uma bibliografia. Começamosa ler edecidimos estudar Filosofia. (Entrevista com H ugo César da SilvaTavares, realizada em 2004, cf. Ferreira, 2007, p. 82).

Atitude semelhante Padre Vaz manteve com Raul Landim Filho, um dos criadores da AN POF, da Associação Nacional de Estudos do Século XVII, da Revista Analytica e do recém-criado Programa de Pós-Graduação em Lógica e O ntologia na UFRJ. A orientação zelosa e constante de Pe. Vaz chegou a Raul Landim quando este ainda era adolescente, como já mencionado, cursando 0 ginásio do Colégio Anchieta do Rio de Janeiro, famoso como local organizado pelos jesuítas para educação das elites. N esse Colégio, teve acesso aos artigos do Padre Vaz, como, por exemplo, "C ristianismo e consciência histórica”, publicado na revista Síntese, periódico da Companhia de Jesus. Posteriormente, conheceu o clérigo pessoalmente, durante seus estudos em Filosofia na Faculdade de Filosofia N ossa Senhora de M edianeira.

Ao referir-se às conversas com o Pe. Vaz, considerou-as fundamentais para 0 estabelecimento de "uma leitura sistemática da obra de M arx, de Santo Tomás e de alguns clássicos da Filosofia, além da leitura do livro do neotomista e jesuíta belga Joseph $\mathrm{M}$ aréchal, intitulado Le point de départ de la metaphysique (M aréchal, 1964), fio condutor de seus estudos filosóficos. Ele não se priva, ainda, de mencionar a forma de sua participação na JU C e na AP, movimento político de esquerda de inspiração cristã.

Eu participei da elaboração do longo manifesto, conhecido como manifesto da PU C-RJ, quando Aldo Arantes (jucista) era o Presidente do D iretório Central dosEstudantes. M ostrei esse manifesto ao padreVaz, quesugeriu algumas modificações imediatamenteincorporadas ao texto [...] C omo as idéias do manifesto exprimiam concepções não estritamente tomistas do homem, da história e da sociedade, o que não era tomista nem conservador só poderia ser marxista, segundo 0 raciocínio simplista. Esse manifesto estevena origem da fundação daAP eserviu de base para um manifesto posterior que marca propriamente a fundação da AP [...]. (N obre; Rego, 2000, p.255). 
A militância de Raul Landim Filho não se resumiu apenas à redação desse documento ${ }^{3}$ que, segundo Paulo Arantes, diretor nacional da JU C, era um texto de fundamentação da educação de base redigido em alta linguagem filosófica (Arantes, 2005, p. 10). A militância estendeu-se também a consultas semanais, "uma espécie de consultoria filosófica e ideológica" que Raul Landim, a conselho de Pe.Vaz, fazia ao pessoal que estava envolvido com o M ovimento de Educação de Base.

Paulo Arantes, ao lembrar-se dos encontros com Padre Vaz em Nova Friburgo, refere-se a Raul Landim como o "discípulo-filósofo, profissional, dileto de Padre Vaz":

Ele(Pe. Vaz) mefez freqüentar um discípulo dele, esse, sim, um discípulo filósofo [...] queeu conheci no Rio de] aneiro eque estava mergulhado na Suma teológica, a consel ho do Vaz. Foi curioso porque, naquelemomento, ele estavafichando aSuma teológica[...] Imaginem [...] fichar a Suma teológica (Arantes, 2005, p. 10).

Continuar investindo na Filosofia dependeu, no entanto, da oportunidade de realizar um doutorado em Filosofia no exterior, porque, como ressaltam os próprios entrevistados, a circulação em centros europeus favoreceu, além de uma formação "sólida em Filosofia", o acúmulo de novos saberes e a reinvenção de novas formas de filosofar.

Aqui, mais uma vez, a passagem pela militância política configura-se como crucial em termos de aquisição social, pois foi graças aos contatos e aos conhecimentos feitos com os religiosos e os militantes nos movimentos de juventude católica que boa parte dos entrevistados acabou por realizar estudos doutorais em Filosofia em centros internacionais na Europa, em particular, na U niversidade C atólica de Louvain, na Bélgica.

Militância política e formação acadêmica no exterior

A passagem pelo campo internacional, de boa parte dos filósofos responsáveis pela criação dos espaços de debates filosóficos, além de contar com as redes institucionais ligadas diretamente com as ordens religiosas nas quais estavam

3. Segundo o próprio Paulo Eduardo Arantes, diretor nacional da JUC em 1963, esse texto passou a ser considerado uma espécie de documento, de texto-base, para a militância católica de esquerda, que se considerava socialista naquele momento. Ver (Arantes, 2005, p. 9).

4. Movimento ligado à alta hierarquia católica (CNBB) e ao Ministério da Educação durante o governo João Goulart e que procurava politizar, especialmente, a população do campo. 
envolvidos durante o trabalho político com os movimentos de juventude, também esteve atrelada às redes de relações sociais estabelecidas durante a permanência nos movimentos católicos que tinham como destino principal a Universidade C atólica de Louvain (UCL). Essas redes, criadas antes mesmo da instauração da ditadura militar no Brasil, acabaram por transformar-se na principal via de acesso, aos estudos doutorais no estrangeiro, para os ex-militantes católicos perseguidos e exilados do país, sobretudo após o Al-5, em 1968.

Ao contrário das redes vinculadas às ordens religiosas, como as ordens dos dominicanos e dos jesuítas, nas quais a escolha e toda a tramitação da circulação dos religiosos, envolvidos ou não nos movimentos políticos, eram de inteira responsabilidade da instituição (do financiamento até o lugar de moradia, passando pela escolha do curso e da universidade), a rede que levou boa parte dos militantes católicos a Louvain (Bélgica) não estava atrelada a uma ordem religiosa em particular. A passagem pela U niversité C atholique de Louvain (UCL) esteve ligada à formação do episcopado latino americano, bem como do seu laicato, como observam Beozzo, em seus estudos sobre a I greja no Brasil (1996), e Antônio M uniz de Rezende, dominicano e assistente intelectual da JUC de Padre Vaz. Segundo Beozzo, parte desse interesse esteve relacionada à preocupação da I greja com a propagação dos ideais da Revolução Cubana ${ }^{5}$. Entre as instâncias que estavam ligadas a essa rede temos: a Conferência $\mathrm{N}$ acional dos Bispos Brasileiros (CN BB), criada em 1952; o Conselho Episcopal Latinoamericano (CELAM ), em 1958; e os movimentos católicos da Juventude (JEC e JUC), criados no final da década de 1930, no Brasil.

Servindo de abrigo político para ex-militantes de esquerda católica, dandoIhes oportunidade de realizar estudos de pós-graduação em Filosofia e em outras áreas das ciências humanas, a Universidade C atólica de Louvain sempre contou com a ajuda privada e pública para a manutenção de bolsas de estudos. A ajuda concedida pela UCL, sobretudo a partir de 1962, aos filósofos exmilitantes, foi iniciativa de um casal de militantes católicos, senhor e senhora Morren-Speth, fundadores, em 1947, do Mouvement Internacional des Intellectuels $C$ atholiques ( $M I I C$ ), e contou praticamente com toda a fortuna pessoal do casal. 0 que chama atenção, no entanto, é o tipo de exigência de-

5. Em 1960, como resultado dos preparativos do Concílio Vaticano II, a Igreja lançou um programa de apoio, sem paralelo na história, para qualificar o clero e, em menor medida, o laicato da América Latina, nas universidades européias. O programa foi lançado primeiramente em Roma, depois na Bélgica (Universidade Católica de Louvain) e na França (Institut Catholique de Paris e Centre Economie e Humanisme, fundado pelo Pe. Lebret). Dois anos depois, o Colégio PróAmérica Latina de Louvain passou a oferecer um curso de treinamento para candidatos leigos e religiosos interessados nas pastorais a serem criadas em países do Cone Sul. O curso compreendia o ensino de português e espanhol, além de disciplinas sobre cultura, economia e pastoral. Ver Beozzo, 1996, pp. 17- 36. 
mandada para a concessão de bolsas, conforme afirma Guy Bajoit, secretário do serviço de estudantes estrangeiros da Universidade. Segundo o secretário, a descrição do itinerário dos candidatos era indispensável para a obtenção da bolsa: "Lesétudiantsdevaient prouver qu'ilsétaient desbonscatholiques, qu'ilsavaient fait de bonnes choses en tant que catholiques" (Entrevista com G uy Bajoit, realizada em 2005, cf. Ferreira, 2007, p. 99). Guy Bajoit ressalta, ainda, o fato de 0 Brasil, em 1967, ser considerado país prioritário no recebimento de bolsas de estudos ${ }^{6}$.

Antônio M uniz de Rezende, um dos criadores do Programa de Pós-Graduação em Filosofia da Educação na U nicamp, realizou seus estudos na U niversidade de Louvain, graças a esse tipo de bolsa de estudo.

N ós estávamos em efervescência em B elo H orizontee eu acabei sendo indiciado etivequeviajar. Bom, JosédeAnchieła estava em Louvain. Eu escrevi a eleporquesabia que L ouvain nessemomento estava muito receptiva, muito acol hedora para osbrasi lei rosque tinham dificuldadesdeordem política aqui no Brasil. $\mathrm{N}$ a verdade, havia um acordo entreasinstânciasedesásicas Então, eu, por exemplo, deinício obtiveuma bolsa pela CRB (Conferência dos Religiososdo Brasil). Viajei para Louvain com o apoio dessa instituição religi osa. Lá, obtiveuma bolsa da própria universidade. Essa bolsa eu consegui com M meM orren. Ela fornecia bolsasde etudos. Era um casal muito rico equenunca tevefilhos Eleseram envolvidoscom asatividadessociaisda U nivers dade. Então eles davam bolsaspara etudantesetrangeiros (Entrevista com Antônio M uniz de Rezende, realizada em 2003, cf. Ferreira, 2007, p. 99).

6. No que concerne ao aumento de estudantes do Brasil em Louvain, foi possível localizar, por meio de uma lista concedida pela secretaria geral da universidade, 455 estudantes brasileiros para o período de 1960 a 1980. Esses dados, no entanto, não permitem elaborar uma evolução da quantidade de estudantes em todos os anos letivos. Por isso, trabalhou-se com dados dispersos encontrados graças a uma pesquisa nos arquivos e anuários da universidade Católica de Louvain. A partir das informações disponíveis, observa-se que, no ano letivo de 1958-59, apenas 5 estudantes brasileiros estavam na UCL, dentre eles, 3 religiosos. No ano letivo seguinte, 19591960, esse número passou para 8, dentre os quais, 5 religiosos. No ano letivo 1962-63, observouse um aumento considerável: 22 estudantes e, no ano seguinte, 25 (apenas 3 religiosos). A consulta aos arquivos da universidade, em particular aos dados fornecidos nos anuários da CIEE, associação que promovia prestação de serviços aos estudantes (moradia, seguro saúde, restaurante universitário), além de atividades culturais (bailes, cinemas, seminários e conferências), aponta os anos letivos de 1967-68 e 1969-70 como os mais significativos, porque dos 455 estudantes brasileiros, pelo menos 230 chegaram à Universidade nesse período, considerada a época de maior repressão política no Brasil. Todos esses dados foram coletados por meio de uma pesquisa empírica realizada nos arquivos da Universidade Católica de Louvain, em maio de 2005. 
0 mesmo modo de acesso ao internacional - ao Instituto Superior de Filosofia, na U niversidade Católica de Louvain, onde realizou sua tese de doutorado - foi utilizado por José de Anchieta Corrêa, ex-presidente da SEAF. 0 filósofo entrou nos movimentos católicos de esquerda quando fazia seus estudos secundários no Colégio Estadual de Belo H orizonte, fortemente influenciado por Frei M atheus Rocha. Após o desmantelamento da JU C e da AP, tendo participado da fundação desta última, ele foi condenado e ficou preso durante quase um ano até conseguir exilar-se na Bélgica e estudar na U niversidade Católica de Louvain (UCL), em 1966. Contou, para tanto, com a ajuda de uma bolsa de estudos da própria instituição da U CL, cedida graças aos religiosos envolvidos no trabalho de militância política.

Eu tinha sido preso econdenado por dez anos, cinco anospor ter fundado a AP ecinco por corrupção à juventude. Fiquei preso com presoscomunsquaseum ano. D epoisconsegui um habeascorpus. M inha sogra tinha relação com políticos Fui para o Rio tentar me exilar [...] fui com uma carta para entregar ao Alceu Amoroso Lima. Ao mesmo tempo, eu já tinha escrito para Louvain. Informei tudo o que podia para provar querealmenteeu precisava da bolsa [...] eu já estava desesperado quando finalmentesaiu a bolsa pra Louvain. Eu fui com minha mulher emeusdoisfilhos (Entre vistacom J osédeAnchietaC orrêa, realizadaem 2004, cf. Ferreira, 2007, p. 92).

\section{Considerações finais}

A passagem por essas instituições no exterior bem como pela militância política com os religiosos dominicanos e jesuítas, resultou numa série de transformações para a própria disciplina: 1) a criação de espaços de discussões de Filosofia e de reconhecimento e garantia social para os praticantes da disciplina no sistema universitário do país (SEAF e AN POF); 2) a criação de espaços de difusão do conhecimento e a formação de um público específico (revistas especializadas em Filosofia; 3) a constituição de um corpo de professores especializados, produtores e transmissores de novas formas de filosofar.

Assim, embora o aparecimento desses dispositivos esteja relacionado, como dito anteriormente, ao financiamento em pesquisa, derivado da reforma universitária de 1968, e à abertura política dos anos 1980, a reconversão dos saberes apreendidos com o militantismo católico, com a formação oferecida e praticada nos núcleos de assistência intelectual da JEC e JUC, foi indispensável no processo de institucionalização da Filosofia no Brasil. Como visto ao longo do artigo, a ação dos filósofos ex-militantes católicos nesse processo deu- 
se em função da gestão da cultura familiar que possibilitou uma escolarização em colégios e universidades de prestígio marcada pela presença de líderes dos movimentos de juventude católica. A oportunidade de estudar e participar desses movimentos no Brasil, com o respaldo do jesuíta Padre Vaz e do dominicano Frei $M$ atheus, além da oportunidade de circulação por instituições de ensino no exterior, permitiu, por exemplo, ultrapassar o treinamento fornecido pela repetição das 100 teses tomistas em latim, presente, sobretudo, na formação nos colégios católicos; e estabelecer novos lugares e formas de filosofar.

N esse sentido, como se pode observar, a relação entre militância política, em particular, a militância católica e a Filosofia no Brasil, longe de ser uma relação direta e simples, apesar de freqüente, como aponta Ricardo M usse (2001), esteve atravessada por uma série de modos de socialização - estudos filosóficos, redação e discussões intelectuais, organização de grupos e reuniões, freqüência às bibliotecas, além da elaboração de teses e dissertações de mestrado em centros renomados em Filosofia - sem os quais dificilmente poderia ser travada alguma forma de vínculo entre Filosofia e militância. A freqüência e 0 aprendizado com esses saberes podem ser considerados, portanto, como uma chave importante para entender de que forma a militância política em movimentos de juventude católica pôde ser reconvertida em recursos sociais diferenciadores na constituição do campo filosófico brasileiro.

\section{Referências bibliográficas}

ARAN TES, P. E. 0 fio da meada. São Paulo: Paz eTerra, 1996.

ARAN TES, P. E. U m departamento francês deultramar: estudos sobre a formação da cultura filosóficauspiana. Rio deJaneiro: Paz \& Terra, 1994.

ARAN TES, P. E. Um depoimento sobrePe. Vaz. Síntese, n. 102, 2005. pp. 9-12.

BAJO IT, G uy. Lesbourses dela coopération au développement. Portrait d'un couple: $H$ è̀èneet Lucien M orren-Speth. Bélgica: U niversidadeC atólica de Louvain, 2002.

BEOZZO , O scar. A igreja no Brasil, de oão XXIII a João Paulo II deM edellín a Santo. Petrópolis: Vozes, 1996.

FERREIRA, D aniela M aria. Entrelenational etl'internacional: lechamp dela philosophieau Brésil. 2001. 190p. Diplomed'Etudes Approfondies. EcoledesH autesEtudesem Sciences Sociales, Paris.

FERREIRA, D anielaM aria. Conversão ereconversão: a circulação internacional dos filósofosde origem católica. 2007. 197p. Tese (D outorado em Educação). Faculdade de Educação, U nicamp, Campinas. 
FILH O, Raul Ferreira Landim. N otas sobreo conceito de pesquisa em Filosofia. Cadernosde H istória e Filosofia da Ciência, CLE/U nicamp, n. 5, p. 129, 1983. FILH O, Raul Ferreira Landim. Pe. H enriqueVaz, um filósofo cristão. Analytica, Rio deJaneiro, v. 6, n. 1, p. 9-17, 2002.

N O BRE, M arcos; REG O, J oséM arcio. Conversascom filósofosbrasileiros. São Paulo: Editora 34, 2000.

N O BRE, M arcos; REG O, José M arcio. A Filosofia da U SP sob a ditadura militar. N ovos Estudos- Cebrap, São Paulo, p. 137-150, 1999.

M arechal, Joseph. Lepoint dedépart de la métaphysique, Paris : D esclée de Brouwer, 1964.

M USSE, Ricardo. D amilitância políticaà Filosofia: um panorama daFilosofia brasileira. Folha deS.Paulo, São Paulo, 2001. Jornal deResenha.

PAIM , Antônio. 0 ensino da Filosofia posterior à criação do Curso Superior deF ilosofia, no Brasil desclea Colônia. 0 ensino deFilosofia desdea colônia (apostila decurso), Rio deJ aneiro, s.d., p. 208. Disponível em: «ttp://ler.letras.up.pt/uploads/ficheiros/1367.pdf>, 1984. Aceso em junho de 2007.

RIDEN TI, M arcelo. 0 fantasma da revolução brasileira. São Paulo: Unesp, 1993.

RID EN TI, M arcelo. Ação Popular: cristianismo emarxismo. In: REIS FILH O , AARÃO , D aniel; RID EN TI, M arcelo (O rg.) H istória do marxismo no Brasil. Partidoseorganizações dos anos 20 aos 60. Campinas: Ed. da U nicamp, 2002. p.213-282. v. 5

SO UZA, H erbert. CristianismoeH istória. São Paulo: EdiçõesLoyola, 1982.

Recebido em 31 de outubro de 2008 eaprovado em 06 demarço de2009. 